\title{
Crescimento, distribuição e acúmulo de cobre e zinco em plantas de pinhão-manso ${ }^{1}$
}

\author{
Growth, distribution and content of copper and zinc in Jatropha curcas L. plants
}

\author{
Lucia Helena Garófalo Chaves ${ }^{2 *}$, Evandro Franklin de Mesquita ${ }^{3}$, Diva Lima de Araujo e Clébia Pereira de \\ França $^{5}$
}

\begin{abstract}
Resumo - Pesquisas referentes à extração de metais pesados por planta de pinhão-manso ainda são incipientes. Com a perspectiva dessa planta ser utilizada na recuperação de solos contaminados, objetivou-se, com este trabalho, avaliar os efeitos do cobre e zinco no crescimento do pinhão-manso e o acúmulo e distribuição desses metais na planta. Dois experimentos foram realizados em delineamentos inteiramente casualizados: no primeiro, os tratamentos consistiram em cinco doses de cobre $\left(0 ; 25 ; 50 ; 75\right.$ e $\left.100 \mathrm{mg} \mathrm{dm}^{-3}\right)$ e, no segundo, quatro doses de zinco $\left(0 ; 50 ; 100\right.$ e $\left.150 \mathrm{mg} \mathrm{dm}^{-3}\right)$, com três repetições. Aos 50; 70; 90 e 110 dias após o semeio, foram avaliados: altura da planta, diâmetro caulinar e área foliar. No final do experimento as plantas foram colhidas e avaliados os teores de cobre e zinco nos tecidos vegetais. Amostras de solo de cada vaso foram coletadas e submetidas às analises químicas. As plantas de pinhão-manso, durante o período experimental, são tolerantes aos tratamentos utilizados, no entanto, doses de cobre e zinco no solo acima de 75 e $50 \mathrm{mg} \mathrm{dm}^{-3}$, respectivamente, depreciam o crescimento das mesmas. Os acúmulos de cobre e zinco nas plantas obedeceram às seguintes ordens, respectivamente: folha $>$ raiz > caule; caule $>$ folha $>$ raiz. A translocação do zinco foi maior que a do cobre nas plantas.
\end{abstract}

Palavras-chave - Jatropha curcas L. Fitorremediação. Cu. Zn. Metais pesados.

\begin{abstract}
Researches concerning the extraction of heavy metals by Jatropha curcas L. plants are still preliminary and incomplete. With the prospect of this plant to be used in phytoremediation of polluted soils, this study aimed to evaluate the effect of copper and zinc in the initial development of Jatropha curcas L. and accumulation and distribution of these elements in this plant. Two experiments were carried out in design completely randomized with three replications; the first one with five copper $\left(0 ; 25 ; 50 ; 75 ; 100 \mathrm{mg} \mathrm{dm}^{-3}\right)$ and the second with four zinc $\left(0 ; 50 ; 100 ; 150 \mathrm{mg} \mathrm{dm}^{-3}\right)$ treatments. At 50; 70; 90 and 110 DAS, were evaluated: plant height, stem diameter and leaf area. At the end of the experiment the plants were harvested and assessed the levels of copper and zinc in plant tissues. Soil samples were collected from each pot and subjected to chemical analysis. The Jatropha curcas L plants, during the experimental period are tolerant to the treatments, however, copper and zinc levels in soil above 75 and $50 \mathrm{mg} \mathrm{dm}^{-3}$, respectively, affect their growth. The copper and zinc concentrations in the plants were ranked in the following order, respectively: leaf $>$ roots $>$ stem; stem $>$ leaf $>$ root. Zinc translocation was higher than copper in the plants.
\end{abstract}

Key words - Jatropha curcas L. Fhytoremediation. Cu. Zn. Heavy metal.

\footnotetext{
* Autor para correspondência

${ }^{1}$ Recebido para publicação em 08/06/2009; aprovado em 13/04/2010

Trabalho de pesquisa desenvolvido pelo Departamento de Engenharia Agrícola da Universidade Federal de Campina Grande

${ }_{2}^{2}$ Departamento de Engenharia Agrícola, CTRN/UFCG, Avenida Aprígio Veloso n. 882, Campina Grande-PB, Brasil, 58109-850, lhgarofalo@hotmail.com

${ }_{3}^{3}$ Programa de Pós-Graduação em Engenharia Agrícola, CTRN/UFCG, Campina Grande-PB, Brasil, elmesquita4@yahoo.com.br

${ }^{4}$ Programa de Pós-Graduação em Engenharia Agrícola, CTRN/UFCG, Campina Grande-PB, Brasil, dyva-araujo@hotmail.com

${ }^{5}$ Programa de Pós-Graduação em Engenharia Agrícola, CTRN/UFCG, Campina Grande-PB, Brasil, clebia_franca@hotmail.com
} 


\section{Introdução}

Os metais pesados são elementos que ocorrem naturalmente no solo, sendo que alguns deles, como é o caso do cobre $(\mathrm{Cu})$ e zinco $(\mathrm{Zn})$, considerados micronutrientes, são essenciais para os vegetais. Entretanto, quando presentes em elevadas concentrações, podem causar danos ao ambiente e à cadeia alimentar. As fontes antropogênicas de metais pesados são provenientes das atividades industriais, agrícolas e urbanas (BAKER, 2000), sendo o solo um dos principais receptores de tais metais.

No solo os metais pesados podem ocorrer na forma iônica ou complexada na solução do solo, como íons trocáveis, presos aos complexos de troca, como íons quelatos em complexos orgânicos ou organominerais, incorporados em sesquióxidos precipitados ou sais insolúveis ou presos nas estruturas cristalinas dos minerais primários ou secundários. No caso do $\mathrm{Cu}$, suas formas mais comuns na solução do solo são os quelatos orgânicos solúveis (KABATA-PENDIAS; PENDIAS, 1992), sendo considerado um elemento pouco móvel nos solos. A forma mais comum do $\mathrm{Zn}$ é a iônica e, por ser fortemente retido pelas argilas e pela matéria orgânica, torna-se praticamente imóvel no solo, porém, comparativamente, apresenta maior mobilidade que o Cu (SIMÃO; SIQUEIRA, 2001).

Os teores normais de $\mathrm{Cu}$ no solo e nas plantas podem variar de 2 a $250 \mathrm{mg} \mathrm{kg}^{-1}$ e de 5 a $20 \mathrm{mg} \mathrm{kg}^{-1}$, respectivamente (BOWEN, 1979). Em concentrações no solo acima da faixa de 60 a $125 \mathrm{mg} \mathrm{kg}^{-1}$ ocorre toxidez do elemento e as concentrações nas plantas de 20 a $100 \mathrm{mg} \mathrm{kg}{ }^{-1}$ são consideradas críticas, causando danos ao tecido e ao alongamento das raízes, alterações na permeabilidade da membrana, inibição do transporte de elétrons fotossintéticos, imobilização do elemento nas paredes e vacúolos e clorose (KABATA-PENDIAS; PENDIAS, 1992). Solos com teores de $\mathrm{Zn}$ abaixo de 10 a $20 \mathrm{mg} \mathrm{kg}^{-1}$ são considerados deficientes, enquanto aqueles com teores entre 25 a $150 \mathrm{mg} \mathrm{kg}^{-1}$ apresentam o metal em quantidades ideais à nutrição das plantas. Quando a concentração atinge patamares maiores que $400 \mathrm{mg} \mathrm{kg}^{-1}$, passa a ser tóxico às plantas cujos sintomas são caracterizados por redução no crescimento e clorose (MATTIAZZO-PREZOTTO, 1994).

Ao mesmo tempo em que o excesso de metais nos solos afeta o desenvolvimento das espécies vegetais, a vegetação é uma alternativa para a recuperação de solos degradados pelo excesso desses elementos (MARQUES et al., 2000). Este método, conhecido como fitorremediação, visa remover, transferir, estabilizar ou destruir elementos nocivos (BURKEN, 2002).

O pinhão-manso (Jatropha curcas L.), da família das Euphorbiaceae, tem sido citado na literatura como uma cultura rústica, que sobrevive bem em condições de solos marginais de baixa fertilidade natural se adaptando às mais diversas condições edafoclimáticas (ARRUDA et al., 2008; SATURNINO et al., 2005). O óleo extraído das suas sementes serve para lustrar e envernizar móveis, é utilizado na saboaria, na indústria de tintas e como combustível nos motores Diesel. Além de produzir o óleo, esta espécie tem sido usada como cerca viva e vem sendo plantada com sucesso, visando o controle da erosão e a contenção de encostas e dunas, sendo apontada como uma planta capaz de recuperar áreas degradadas (SATURNINO et al., 2005).

Poucos são os estudos sobre as exigências nutricionais do pinhão-manso, no entanto, Gusmão et al. (2007), trabalhando com diagnose por subtração, observaram que a ausência de $\mathrm{Zn}$ causou, nestas plantas, redução nos internódios e maior número de folhas. Em trabalho semelhante, Andrade et al. (2007) observaram que a omissão de $\mathrm{Cu}$ e Zn não provocou sintomas de deficiência nas plantas. Segundo observações feitas por Laviola \& Dias (2008), avaliando a concentração e o acúmulo de nutrientes em folhas de pinhão-manso, os referidos elementos foram os que menos se acumularam nas folhas das plantas.

Considerando a falta de conhecimento sobre o comportamentodasplantasdepinhão-mansoquandocultivadas em solos com altos teores de $\mathrm{Cu}$ e $\mathrm{Zn}$ e a perspectiva dessa planta ser utilizada na fitorremediação destes solos, objetivouse com este trabalho avaliar o efeito destes elementos no desenvolvimento inicial da planta quando submetida a teores elevados dos mesmos e o acúmulo e distribuição do $\mathrm{Cu}$ e $\mathrm{Zn}$ na planta de pinhão-manso.

\section{Material e métodos}

Dois experimentos foram realizados em casa de vegetação pertencente ao Departamento de Engenharia Agrícola da Universidade Federal de Campina Grande, no período de julho a outubro de 2008, utilizando-se vasos plásticos com $25 \mathrm{~L}$ de capacidade, perfurados na base para permitir drenagem, os quais foram preenchidos com $22 \mathrm{~kg}$ de substrato. O mesmo era constituido de solo franco-arenoso classificado como NEOSSOLO QUARTZARÊNICO (EMBRAPA, 1999), coletado na camada superficial do solo ( $0-0,20 \mathrm{~m}$ de profundidade), tendo como atributos químicos: $\mathrm{pH}\left(\mathrm{H}_{2} \mathrm{O}\right)=5,8 ; \mathrm{Ca}=2,47 \mathrm{cmol}_{\mathrm{c}} \mathrm{kg}^{-1} ; \mathrm{Mg}=$ $2,57 \mathrm{cmol}_{\mathrm{c}} \mathrm{kg}^{-1} ; \mathrm{Na}=0,52 \mathrm{cmol}_{\mathrm{c}} \mathrm{kg}^{-1} ; \mathrm{K}=0,19 \mathrm{cmol}_{\mathrm{c}}$ $\mathrm{kg}^{-1} ; \mathrm{H}=0,76 \mathrm{cmol}_{\mathrm{c}} \mathrm{kg}^{-1} ; \mathrm{Al}=0,0 \mathrm{cmol}_{\mathrm{c}} \mathrm{kg}^{-1} ;$ matéria orgânica $=3,8 \mathrm{~g} \mathrm{~kg}^{-1} ; \mathrm{P}=5,9 \mathrm{mg} \mathrm{kg}^{-1} ; \mathrm{Zn}=4,17 \mathrm{mg} \mathrm{dm}^{-3}$; $\mathrm{Cu}=6,23 \mathrm{mg} \mathrm{dm}^{-3}$.

Os experimentos foram instalados em delineamento inteiramente casualizado, com três repetições, sendo um deles 
com cinco doses de $\mathrm{Cu}\left(0 ; 25 ; 50 ; 75\right.$ e $\left.100 \mathrm{mg} \mathrm{dm}^{-3}\right)$ e um outro com quatro doses de $\mathrm{Zn}\left(0 ; 50 ; 100\right.$ e $\left.150 \mathrm{mg} \mathrm{dm}^{-3}\right)$, perfazendo o total de quinze e doze unidades experimentais, respectivamente, utilizando-se como fontes dos elementos cloreto de cobre e cloreto de zinco. O substrato de cada unidade experimental recebeu uma adubação equivalente a $100 \mathrm{mg} \mathrm{kg}^{-1}$ de $\mathrm{N}, 300 \mathrm{mg} \mathrm{kg}{ }^{-1}$ de $\mathrm{P}_{2} \mathrm{O}_{5}$ e $150 \mathrm{mg} \mathrm{kg}^{-1}$ de $\mathrm{K}_{2} \mathrm{O}$, tendo sido utilizados como fontes de nutrientes a uréia, o superfosfato triplo e o cloreto de potássio, respectivamente. $\mathrm{O} \mathrm{Zn}$, o $\mathrm{Cu}$, o fósforo e $30 \%$ da dose de potássio foram misturados com o substrato antes do preenchimento das unidades experimentais. O restante da dose de potássio e a dose de nitrogênio foram parceladas em três vezes e aplicadas quinzenalmente, a partir do desbaste das plantas, dissolvidos na água de irrigação.

Cada unidade experimental recebeu três sementes de pinhão-manso, tendo permanecido após o desbaste, realizado vinte e cinco dias após o semeio (DAS), uma planta por unidade. Durante todo o período experimental (110 dias), o solo foi mantido com umidade corresponde a $80 \%$ da capacidade de campo, tendo sido monitorada diariamente, utilizando-se sonda de Diviner 2000, através de um tubo de acesso instalado em cada unidade experimental.

Aos 50; 70; 90 e 110 DAS, foram avaliadas altura de planta, mensurada do colo a base da folha mais jovem de cada planta; diâmetro do caule, mensurado na região do colo da planta com uso de paquímetro; número e comprimento de folhas, tendo como critério para a contagem das mesmas o comprimento mínimo de $0,03 \mathrm{~m}$. A área foliar (AF) foi calculada de acordo com o método de Wendt (1967), utilizando a fórmula $\log (\mathrm{Y})=\Sigma\{-0,346$ $+[2,152 \mathrm{x} \log (\mathrm{X})]\}$, sendo $\mathrm{Y}$ a área foliar em $\mathrm{cm}^{2}$ e X o comprimento da nervura central da folha em $\mathrm{cm}$.

Ao final do experimento, os substratos das unidades experimentais foram secos ao ar, passados em peneira com $2 \mathrm{~mm}$ de malha e analisados quimicamente, determinandose os teores de $\mathrm{Cu}$ e $\mathrm{Zn}$ presentes nos mesmos, utilizandose o extrator Mehlich-1. As plantas foram colhidas, sendo o material vegetal separado em raízes, caules e folhas, o qual, depois de lavado em água destilada e seco em estufa de circulação forçada de ar a $70^{\circ} \mathrm{C}$, até peso constante, foi pesado e moído em moinho tipo Wiley. Posteriormente, efetuou-se a digestão nitroperclórica do material para determinação, nos extratos, de $\mathrm{Cu}$ e $\mathrm{Zn}$ por espectrofotometria de absorção atômica. Os teores destes elementos presentes nos substratos também foram determinados por espectrofotometria de absorção atômica.

$\mathrm{O}$ acúmulo (A) do $\mathrm{Cu}$ e do $\mathrm{Zn}$ nas folhas, caules e raízes das plantas $(\mu \mathrm{g})$ foi calculado pela expressão $\mathrm{A}=(\mathrm{MSC}$, ou MSF ou MSR (mg) x Concentração do elemento $\left.\left(\mathrm{mg} \mathrm{kg}^{-1}\right)\right) / 1000$, onde MSC = massa seca dos caules; $\mathrm{MSF}=$ massa seca das folhas; $\mathrm{MSR}=$ massa seca das raízes. A quantidade total de $\mathrm{Cu}$ e de $\mathrm{Zn}$ acumulada na planta foi calculada pelo somatório das quantidades acumuladas destes elementos em cada parte da planta. A partir desta quantidade total, calculou-se a porcentagem de acúmulo dos metais para cada parte da planta. De acordo com Abicheque e Bohnen (1998), calculou-se o índice de translocação (IT) dos elementos, dado em porcentagem, pela relação IT $=$ (Quantidade acumulada na parte aérea / Quantidade acumulada na planta) x 100.

Os dados foram analisados através da análise de variância e análise de regressão, utilizando-se o programa Assistat versão 7.5 beta (2008).

\section{Resultados e discussão}

Os teores totais de $\mathrm{Cu}$ encontrados no solo, após a colheitadasplantas(teorfinal), correspondentesaostratamentos $0 ; 25 ; 50 ; 75$ e $100 \mathrm{mg} \mathrm{dm}^{-3}$ foram, respectivamente, 0,40 ; 13,$32 ; 30,75 ; 27,77$ e $60,35 \mathrm{mg} \mathrm{dm}^{-3}$. Com exceção do teor $60,35 \mathrm{mg} \mathrm{dm}^{-3}$, os demais não são considerados de risco para o ambiente uma vez que estão abaixo do valor de referência de qualidade do solo (VRQ), $35 \mathrm{mg} \mathrm{dm}^{-3}$, sugerido pela CETESB (2007).

Os teores de $\mathrm{Cu}$ que permaneceram no solo das unidades experimentais, após a colheita das plantas (teores finais), variaram em função dos teores iniciais do elemento presentes nestas unidades (teores existentes no solo + teores aplicados como tratamentos) (Figura 1), cujas porcentagens corresponderam a 6,$37 ; 42,66 ; 54,69$; 34,18 e $56,81 \%$ em relação aos tratamentos $0 ; 25 ; 50 ; 75$ e $100 \mathrm{mg} \mathrm{Cu} \mathrm{dm}^{-3}$, respectivamente.

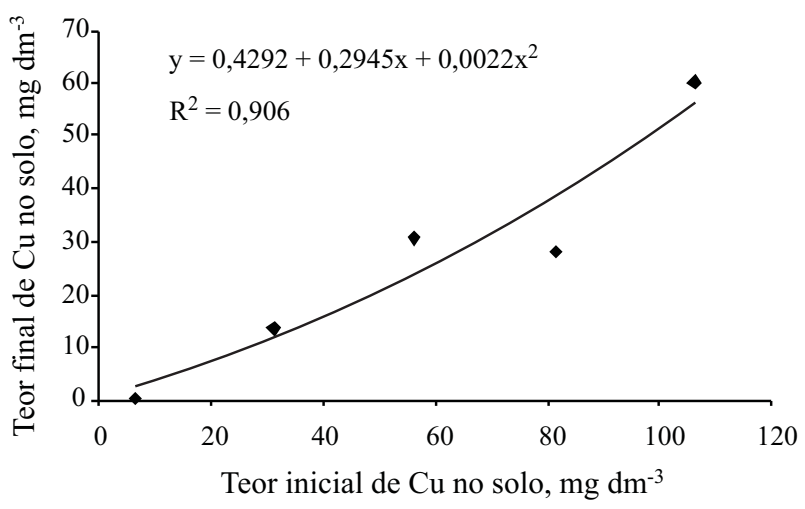

Figura 1 - Variação dos teores de cobre no solo após a coleta das plantas (teores finais) em função dos teores no solo antes do plantio (teores iniciais) 
Os teores de $\mathrm{Zn}$ no solo das unidades experimentais, após a colheita das plantas, os quais corresponderam a 1,44; 24,86; 63,27 e 72,51 mg dm³ $\mathrm{mariar}^{-3}$ em função dos teores iniciais do elemento presentes no solo (Figura 2). Os teores finais correspondentes aos dois maiores tratamentos ficaram acima de $60 \mathrm{mg} \mathrm{kg}$, , valor este considerado de referência de qualidade de solo, segundo CETESB (2007). As porcentagens de $\mathrm{Zn}$ que permaneceram no solo após a colheita das plantas corresponderam a 34,49; 45,9; 60,74; e 47,03\% em relação aos tratamentos 0; 50; 100 e $150 \mathrm{mg} \mathrm{dm}^{-3}$, respectivamente.

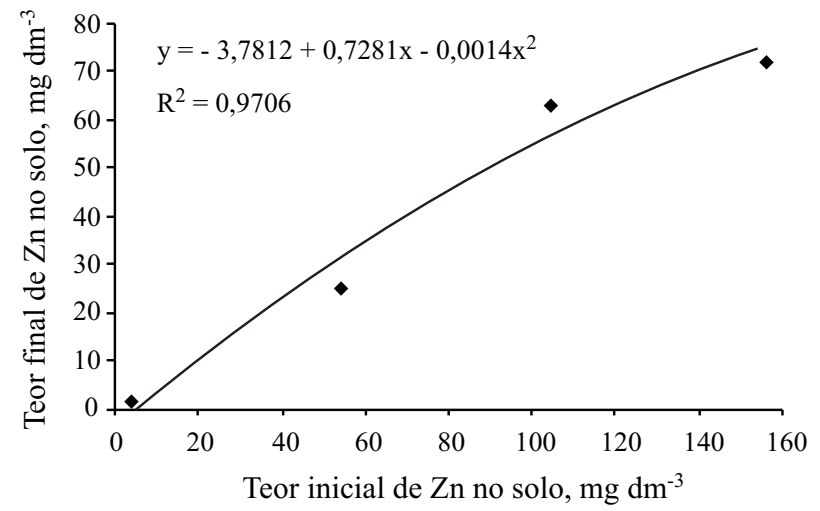

Figura 2 - Variação dos teores de cobre no solo após a coleta das plantas (teores finais) em função dos teores no solo antes do plantio (teores iniciais)
Observa-se nas Figuras 1 e 2 que os teores finais de $\mathrm{Cu}$ e de $\mathrm{Zn}$ no solo, respectivamente, aumentaram em função dos seus teores iniciais, indicando que as quantidades absorvidas destes elementos pelas plantas, provavelmente, não aumentaram na mesma proporção do aumento dos tratamentos. Mesmo assim, as quantidades de $\mathrm{Cu}$ e $\mathrm{Zn}$ absorvidas pelas plantas influenciaram, de alguma forma, no desenvolvimento das mesmas.

Os tratamentos com $\mathrm{Cu}$ não influenciaram, de forma significativa, na altura das plantas, mas influenciaram, a partir dos 70 DAS, no diâmetro caulinar e na área foliar (Tabela 1), discordando de Chaves et al. (2009a) que não encontraram efeito significativo do elemento nas doses de 0 a $4 \mathrm{mg} \mathrm{dm}^{-3}$ sobre estas variáveis de crescimento, justificado neste caso, pelos baixos teores dos tratamentos.

Ao contrário do que foi observado com o $\mathrm{Cu}$, os tratamentos com $\mathrm{Zn}$ influenciaram todas as variáveis de crescimento, em todas as épocas avaliadas, de forma significativa a $1 \%$ de probabilidade (Tabela 1), discordando de Chaves et al. (2009a), que avaliaram o efeito de $\mathrm{Zn}$ com doses variando de 0 a $8 \mathrm{mg} \mathrm{dm}^{-3}$, em plantas de pinhão-manso.

As equações de regressão ajustadas entre os tratamentos e as variáveis de crescimento, que foram influenciadas de maneira significativa pelos mesmos, são apresentadas na Tabela 2 .

Tabela 1 - Resumo das análises de variância (Significância dos Quadrados Médios) referentes aos dados de altura de planta, diâmetro caulinar e área foliar obtidos ao longo do período experimental, em função dos tratamentos com cobre e zinco

\begin{tabular}{|c|c|c|c|}
\hline \multirow[b]{2}{*}{ Tratamentos } & \multicolumn{3}{|c|}{ Significância do Quadrado Médio } \\
\hline & Altura de Planta & Diâmetro Caulinar & Área Foliar \\
\hline & \multicolumn{3}{|c|}{50 dias após a semeadura } \\
\hline Cobre & ns & ns & ns \\
\hline \multirow[t]{2}{*}{ Zinco } & $* *$ & $* *$ & $* *$ \\
\hline & \multicolumn{3}{|c|}{70 dias após a semeadura } \\
\hline Cobre & ns & ns & $*$ \\
\hline \multirow[t]{2}{*}{ Zinco } & $* *$ & $* *$ & $* *$ \\
\hline & \multicolumn{3}{|c|}{90 dias após a semeadura } \\
\hline Cobre & ns & $* *$ & $* *$ \\
\hline \multirow[t]{2}{*}{ Zinco } & $* *$ & $* *$ & $* *$ \\
\hline & \multicolumn{3}{|c|}{110 dias após a semeadura } \\
\hline Cobre & ns & ns & $* *$ \\
\hline Zinco & $* *$ & $* *$ & $* *$ \\
\hline
\end{tabular}

\footnotetext{
*,** significativo ao nível de 5 e $1 \%$ de probabilidade, respectivamente; ns não significativo
} 
Tabela 2 - Equações de regressão ajustadas entre altura de plantas, diâmetro caulinar e área foliar, como variáveis dependentes (Y) dos tratamentos com cobre e zinco (x), nas diversas épocas de avaliação

\begin{tabular}{|c|c|c|c|c|c|c|}
\hline \multirow[t]{3}{*}{$\begin{array}{l}\text { Épocas de } \\
\text { avaliação }\end{array}$} & \multicolumn{6}{|c|}{ Equações Ajustadas } \\
\hline & \multicolumn{6}{|c|}{ Tratamentos com cobre } \\
\hline & \multicolumn{3}{|c|}{ Diâmetro Caulinar } & $\mathrm{R}^{2}$ & Área Foliar & $\mathrm{R}^{2}$ \\
\hline 70 DAS & \multicolumn{3}{|c|}{$Y=24,73-0,2616 x+0,0020 x^{2}$} & $0,98^{*}$ & $Y=2135,18-14,28 x$ & $0,73 * *$ \\
\hline $90 \mathrm{DAS}$ & \multicolumn{3}{|c|}{$Y=25,78-0,1940 x-0,0015 x^{2}$} & $0,95^{*}$ & $Y=3441,39-21,91 x$ & $0,70 * *$ \\
\hline \multirow[t]{3}{*}{110 DAS } & \multicolumn{3}{|c|}{$Y=30,20-0,2033 x-0,0015 x^{2}$} & $0,93 * *$ & $Y=4835,68-31,76 x$ & $0,89 * *$ \\
\hline & \multicolumn{6}{|c|}{ Tratamentos con zinco } \\
\hline & Altura de Plantas & $\mathrm{R}^{2}$ & Diâmetro Caulinar & $\mathrm{R}^{2}$ & Área Foliar & $\mathrm{R}^{2}$ \\
\hline $50 \mathrm{DAS}$ & $Y=22,86-0,028 x$ & $0,99 * *$ & $Y=13,72-0,0378 x$ & $0,98^{* *}$ & $Y=707,13-3,326 x$ & $0,99 * *$ \\
\hline 70 DAS & $Y=47,02-0,169 x$ & $0,99 * *$ & $Y=23,82-0,086 x$ & $0,96 * *$ & $Y=2476,02-19,091 x$ & $0,99 * *$ \\
\hline 90 DAS & $Y=62,40-0,242 x$ & $0,99 * *$ & $Y=25,44-0,0828 x$ & $0,98^{* *}$ & $Y=3717,17-20,638 x$ & $0,97 * *$ \\
\hline $110 \mathrm{DAS}$ & $Y=76,53-0,328 x$ & $0,99 * *$ & $Y=30,30-0,1059 x$ & $0,99 * *$ & $Y=5213,58-3,1193 x$ & $0,99 * *$ \\
\hline
\end{tabular}

*, ** significativo ao nível de 5 e $1 \%$ de probabilidade, respectivamente

A altura das plantas diminuiu em função dos tratamentos com Zn (Figura 3), entretanto, pode-se observar que houve diferenças no comportamento das plantas em relação às doses utilizadas nas épocas de avaliação. Até os $50 \mathrm{DAS}$, por exemplo, as plantas foram pouco afetadas pelos tratamentos, tendo em vista que a diferença entre as alturas, apesar de significativa, foi pequena e seus valores foram semelhantes ao encontrado por Silva et al. (2009), 19,64 cm, em plantas de pinhãomanso com 45 DAS, desenvolvidas em solução nutritiva completa. A partir desta época, os tratamentos passaram a ter maior efeito prejudicial sobre o desenvolvimento das

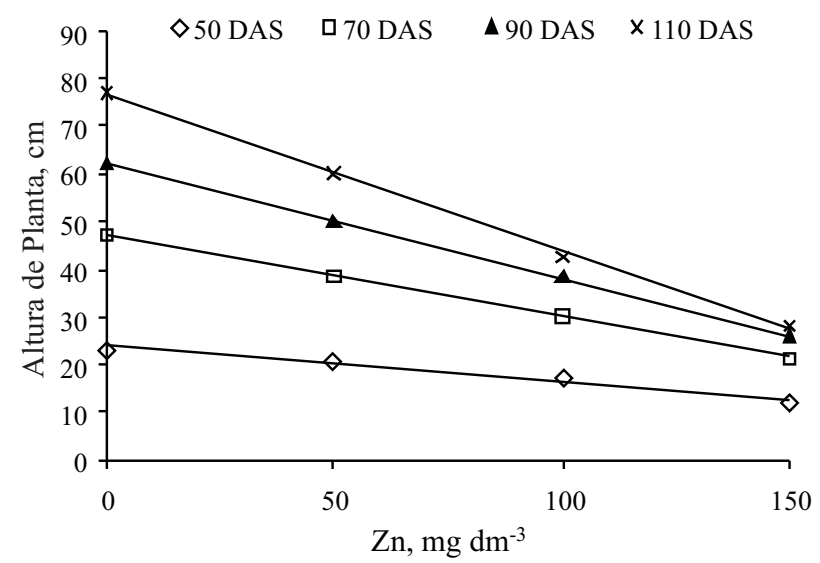

Figura 3 - Variação da altura das plantas em função dos tratamentos com zinco na várias épocas de amostragem plantas o que pode ser notado na Figura 3 pelo aumento da diferença entre as alturas das plantas submetidas aos tratamentos e a testemunha. As plantas submetidas ao maior tratamento foram as mais afetadas durante todo o período experimental, seguidas por aquelas que receberam $100 \mathrm{mg} \mathrm{dm}^{-3}$ aos 110 DAS.

O diâmetro caulinar das plantas diminuiu, de forma significativa, em função dos tratamentos $\operatorname{com} \mathrm{Cu}$ e Zn (Figura 4). Aos 50 DAS, os valores do diâmetro caulinar das plantas testemunhas foram semelhantes ao observado por Silva et al. (2009), $15 \mathrm{~mm}$, em plantas de pinhão-manso com 45 DAS, porém, das demais plantas, nesta mesma época, foram menores. Da mesma forma, os valores do diâmetro caulinar das plantas aos 90 DAS foram menores do que aqueles observados por Chaves et al. (2009a) em plantas de pinhão-manso com a mesma idade, os quais variaram de 30 a $35 \mathrm{~mm}$. Com isto, pode-se dizer que as doses de $\mathrm{Cu}$ e $\mathrm{Zn}$ utilizadas no presente trabalho afetaram de forma negativa o desenvolvimento caulinar das plantas.

Mantendo as tendências já observadas para altura de planta e diâmetro caulinar, a área foliar das plantas diminuiu de forma significativa em função dos tratamentos (Figura 4). Aos 110 DAS, as plantas submetidas à maior dose de $\mathrm{Cu}, 100 \mathrm{mg} \mathrm{dm}^{-3}$, apresentaram uma redução na área foliar em torno de $69,5 \%$ em relação a testemunha. No caso do $\mathrm{Zn}$, as doses de $100 \mathrm{e} 150 \mathrm{mg} \mathrm{dm}^{-3}$ causaram uma redução em torno de 60,1 e 41,9\%, respectivamente, em relação a testemunha, mostrando o efeito depreciativo 


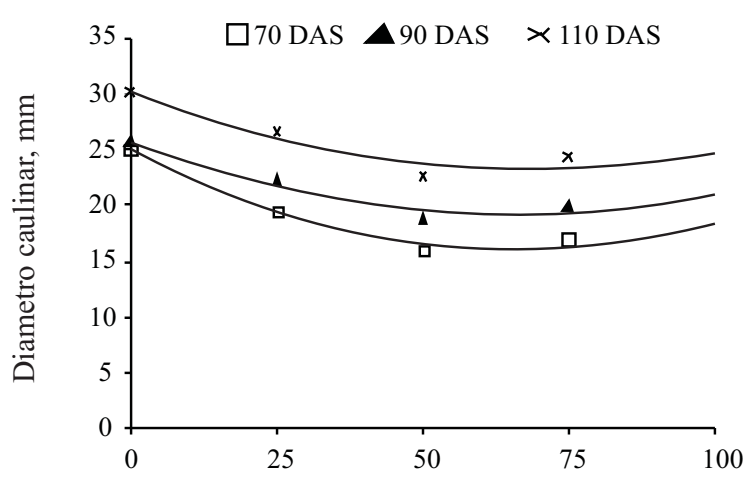

$\mathrm{Cu}, \mathrm{mg} \mathrm{dm} \mathrm{m}^{-3}$

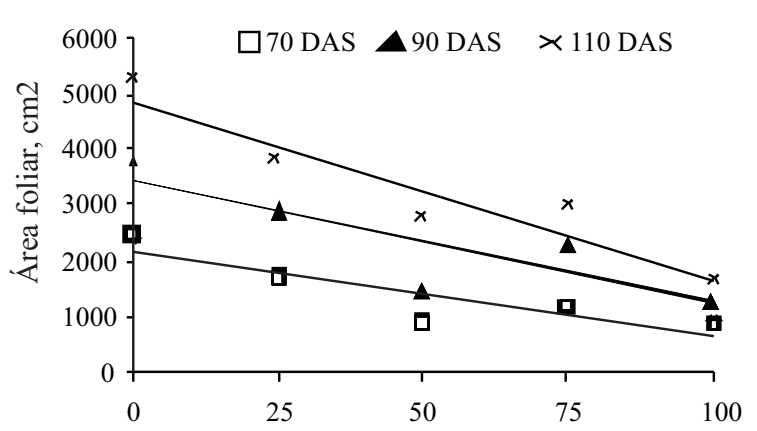

$\mathrm{Cu}, \mathrm{mg} \mathrm{dm}^{-3}$

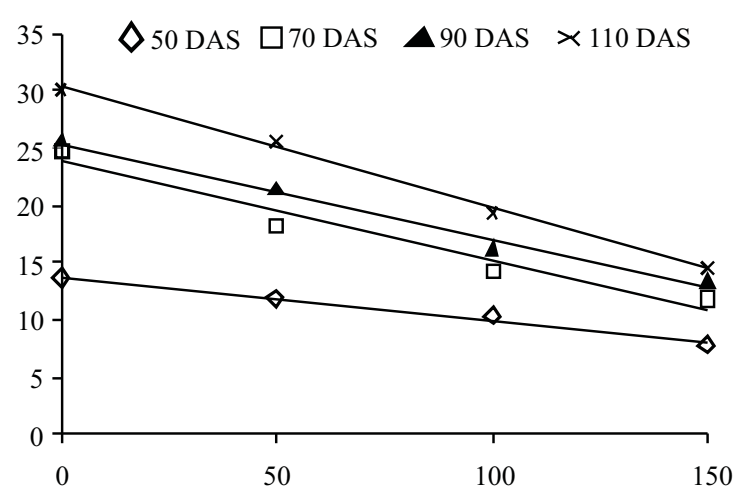

$\mathrm{Zn}, \mathrm{mg} \mathrm{dm}^{-3}$

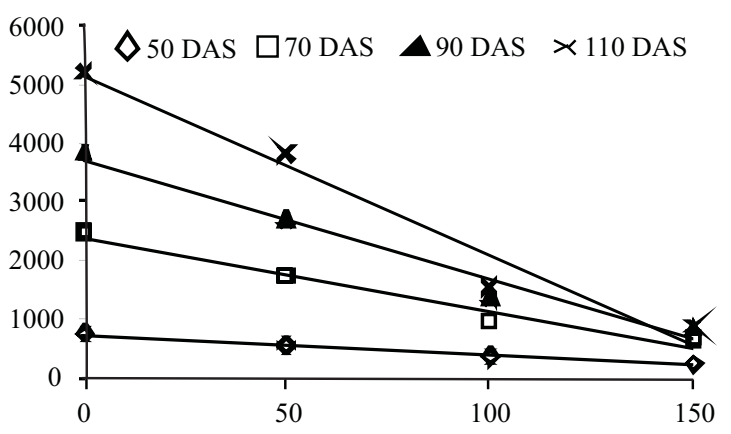

$\mathrm{Zn}, \mathrm{mg} \mathrm{dm}{ }^{-3}$

Figura 4 - Variação do diâmetro caulinar e área foliar em função dos tratamentos com cobre e zinco na várias épocas de amostragem

dos tratamentos no aparelho assimilatório das plantas, o qual está diretamente relacionado com os processos fisiológicos das mesmas.

As produções de matéria seca das raízes, caule e folhas do pinhão-manso, influenciadas pelos tratamentos com $\mathrm{Cu}$ e com $\mathrm{Zn}$ de forma significativa ao nível de $1 \%$ de probabilidade, diminuíram em função das doses crescentes dos elementos (Figura 5).

Segundo Faust e Christians (2000) e Kopittke e Menzies (2006), a redução da massa seca das plantas

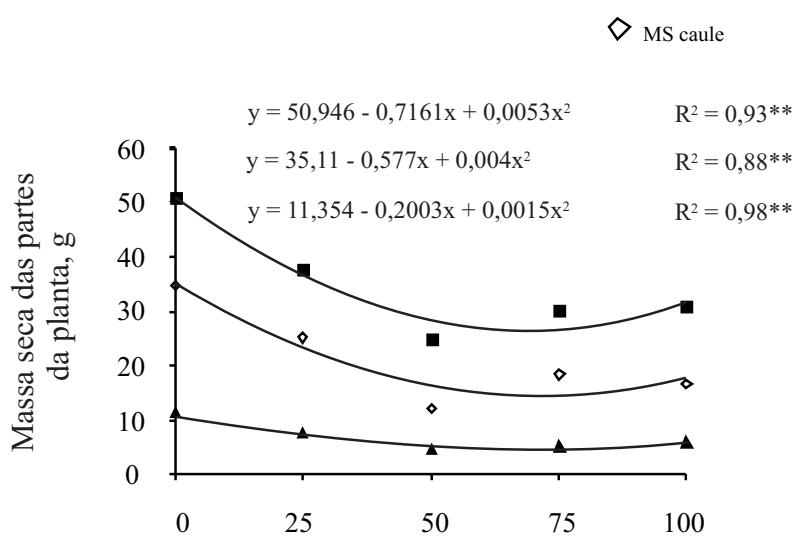

$\mathrm{Cu}, \mathrm{mg} \mathrm{dm}^{-3}$

MS folhas

AS raízes

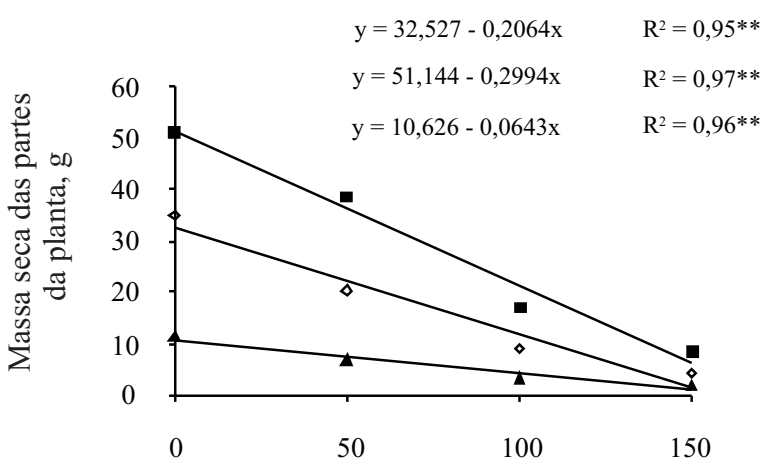

$\mathrm{Zn}, \mathrm{mg} \mathrm{dm}^{-3}$

Figura 5 - Variação da massa seca das raízes, caule e folhas em função das doses de cobre e zinco aplicadas ao solo 
não é devido a uma direta toxidez de $\mathrm{Cu}$ nas mesmas, mas sim, por causa de sua deficiência nutricional causada pelas lesões nas raízes provocadas pelos elevados teores de $\mathrm{Cu}$ no solo. Em relação ao Zn, Malavolta et al. (1997) explicam que a redução na produção de matéria seca em planta submetidas a elevados teores deste elemento é devido ao acúmulo de tampões ("plugs") contendo Zn, no xilema das plantas, os quais dificultam a ascensão da seiva bruta. Zeitouni et al. (2007), avaliando o desenvolvimento de plantas de mamona submetidas aos tratamentos com $\mathrm{Cu}\left(0\right.$ a $\left.40 \mathrm{mg} \mathrm{dm}^{-3}\right)$ e com Zn (0 a $\left.125 \mathrm{mg} \mathrm{dm}^{-3}\right)$, também observaram diminuição na matéria seca das plantas com o aumento das doses dos metais aplicadas ao solo. Teores mais baixos destes elementos, utilizados por Chaves et al. (2009a), não apresentaram efeito significativo sobre a matéria seca de caules e folhas de pinhão-manso.

Os teores de $\mathrm{Cu}$ encontrados nos caules e raízes foram influenciados de forma significativa a 1 e $5 \%$ de probabilidade, respectivamente (Tabela 3), os quais aumentaram de forma linear (Figura 6). De maneira geral, houve aumento nos teores de $\mathrm{Cu}$ em todas as partes das plantas, quando comparado com a testemunha, verificando-se incrementos de até $563,57 \%$ nas raízes, de $150,74 \%$ no caule e de $92,17 \%$ nas folhas.

Os maiores teores do elemento foram observados nas raízes, estando na faixa considerada crítica para as plantas aqueles correspondentes aos tratamentos 50, 75 e $100 \mathrm{mg} \mathrm{dm}^{-3}$. No entanto, considerando os teores na planta como um todo, a partir do tratamento $25 \mathrm{mg} \mathrm{dm}^{-3}$ já são considerados críticos. $\mathrm{Na}$ parte aérea das plantas os maiores teores, em geral, foram observados nas folhas, corroborando com Chaves et al. (2009b). De acordo com Antosiewicz (1992), plantas que apresentam maior teor de $\mathrm{Cu}$ nas raízes comportam-se como plantas indicadoras, ou seja, plantas em que as concentrações do metal na parte interna das mesmas refletem os teores externos (ACCIOLY; SIQUEIRA, 2000; SIMÃO; SIQUEIRA, 2001). Xiaohai et al. (2008), cultivando mamona, uma Euphorbiacea, em solo com $89 \mathrm{mg} \mathrm{Cu} \mathrm{kg}^{-1}$, também observaram maiores concentrações do elemento nas raízes quando comparados ao caule.

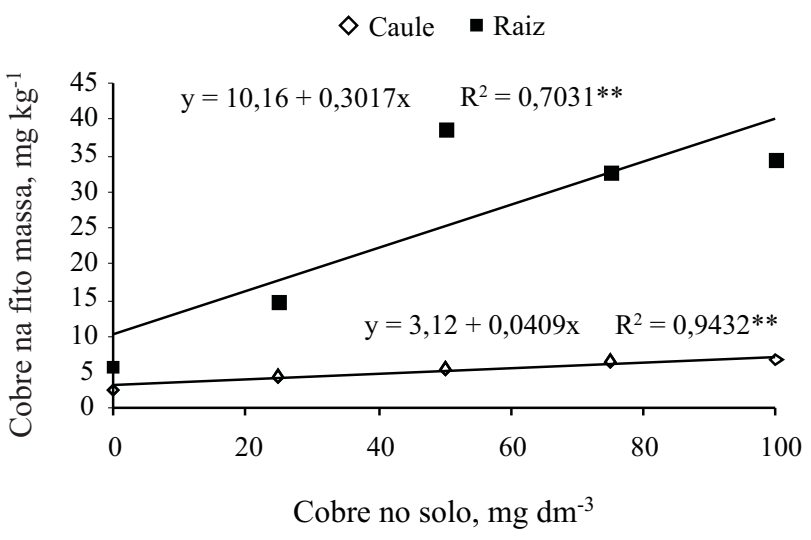

Figura 6 - Variação dos teores de cobre nas raízes e caule do pinhão-manso em função das doses de cobre aplicadas ao solo

Tabela 3 - Resumo das análises de variância (Significância dos Quadrados Médios), teores e conteúdos de cobre e de zinco encontrados nas folhas, caule e raízes das plantas de pinhão-manso, em função dos tratamentos

\begin{tabular}{|c|c|c|c|c|c|c|}
\hline & \multicolumn{3}{|c|}{ Teor, $\mathrm{mg} \mathrm{kg}^{-1}$} & \multicolumn{3}{|c|}{ Conteúdo, $\mu \mathrm{g}$} \\
\hline & Folha & Caule & Raiz & Folha & Caule & Raiz \\
\hline Doses de $\mathrm{Cu} \mathrm{mg} \mathrm{dm}{ }^{-3}$ & ns & $* *$ & $*$ & $*$ & ns & ns \\
\hline 0 & 3,45 & 2,70 & 5,82 & 174,87 & 93,16 & 65,05 \\
\hline 25 & 6,63 & 4,43 & 14,65 & 239,93 & 109,09 & 111,50 \\
\hline 50 & 6,52 & 5,40 & 38,62 & 161,71 & 65,32 & 173,00 \\
\hline 75 & 6,58 & 6,53 & 32,55 & 192,75 & 113,95 & 155,80 \\
\hline 100 & 5,55 & 6,77 & 34,58 & 209,98 & 95,94 & 183,03 \\
\hline Doses de $\mathrm{Zn} \mathrm{mg} \mathrm{dm}{ }^{-3}$ & $* *$ & $* *$ & $* *$ & $* *$ & $* *$ & $* *$ \\
\hline 0 & 27,73 & 33,57 & 42,20 & 1412,83 & 1171,33 & 473,27 \\
\hline 50 & 157,50 & 478,50 & 688,83 & 6105,55 & 9642,50 & 4791,76 \\
\hline 100 & 345,00 & 595,50 & 708,17 & 5814,45 & 5547,72 & 2273,96 \\
\hline 150 & 347,67 & 950,00 & 670,00 & 2639,13 & 4018,50 & 1205,80 \\
\hline
\end{tabular}

*, ** significativo ao nível de 5 e $1 \%$ de probabilidade, respectivamente; ns não significativo 
Apesar do maior teor de $\mathrm{Cu}$ nas raízes, o maior acúmulo relativo do elemento ocorreu nas folhas (Tabela 3), devido, provavelmente, a sua maior quantidade de matéria seca (Figura 5), tendo sido influenciado significativamente a 5\% de probabilidade pelos tratamentos. Plantas com esta característica podem facilitar o processo de distribuição do $\mathrm{Cu}$ nos componentes do ecossistema, tendo-se em vista que as folhas reciclam mais rapidamente que as demais partes da planta (SOARES et al., 2001).

Laviola e Dias (2008), avaliando o teor e acúmulo de $\mathrm{Cu}$ e $\mathrm{Zn}$ em plantas de pinhão-manso cultivado

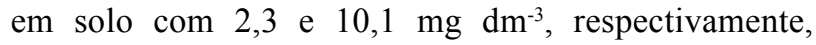
encontraram nas folhas $10 \mathrm{mg} \mathrm{kg}^{-1}$ de $\mathrm{Cu}$ com acúmulo de $11,71 \mu \mathrm{g} /$ planta. A diferença entre estes valores e os encontrados no presente trabalho (Tabela 3) deve-se ao fato das plantas não terem sido adubadas com $\mathrm{Cu}$ e as folhas analisadas terem sido coletadas em plantas com mais de um ano de idade, impossibilitando, por isto, uma comparação entre os resultados destes autores com os do presente trabalho.

Com exceção da testemunha, os teores de $\mathrm{Zn}$ encontrados nas folhas e caules das plantas foram superiores ou estiveram na faixa de 100 a $400 \mathrm{mg} \mathrm{kg}^{-1}$ na matéria seca (Tabela 3 ), considerada prejudicial às culturas (KABATA-PENDIAS; PENDIAS, 1992). Na parte aérea, como um todo, o teor do elemento variou, em média, de 61 a $1298 \mathrm{mg} \mathrm{kg}^{-1}$, variação esta semelhante à encontrada por Zeitouni et al. (2007), na parte aérea de mamoneira, adubada com até $125 \mathrm{mg} \mathrm{Zn} \mathrm{kg}{ }^{-1}$, que foi de 51 a $1188 \mathrm{mg} \mathrm{kg}^{-1}$.

Os tratamentos apresentaram efeito significativo nos teores do $\mathrm{Zn}$ encontrados nas raízes, caule e folhas, observando-se maiores teores nas raízes, com exceção do tratamento $150 \mathrm{mg} \mathrm{dm}^{-3}$ (Tabela 3). Os teores do elemento no caule aumentaram de forma linear, enquanto que nas folhas e raízes aumentaram de forma quadrática (Figura 7), tendo ocorrido um incremento de até $1578,13 \%$ nas raízes, de $2729,90 \%$ no caule e de $1153,77 \%$ nas folhas.

$\mathrm{O}$ acúmulo do $\mathrm{Zn}$ nas raízes, no caule e nas folhas do pinhão-manso foi influenciado, de forma significativa, ao nível de $1 \%$ de probabilidade pelos tratamentos (Tabela 3), tendo ocorrido maiores acúmulos relativos do elemento nos caules e nas folhas. $\mathrm{O}$ acúmulo preferencial no caule pode contribuir para a imobilização do elemento na vegetação, tornando o pinhão-manso promissor para o programa de fitorremediação, desde que tolere as condições de altas dosagens do elemento no solo (SOARES et al., 2001). O teor e o acúmulo de $\mathrm{Zn}$ em folhas de pinhãomanso encontrados por Laviola e Dias (2008) foram $22,70 \mathrm{mg} \mathrm{kg}^{-1}$ e $25,46 \mu \mathrm{g} /$ planta. Este teor é semelhante ao encontrado na planta testemunha do presente trabalho,

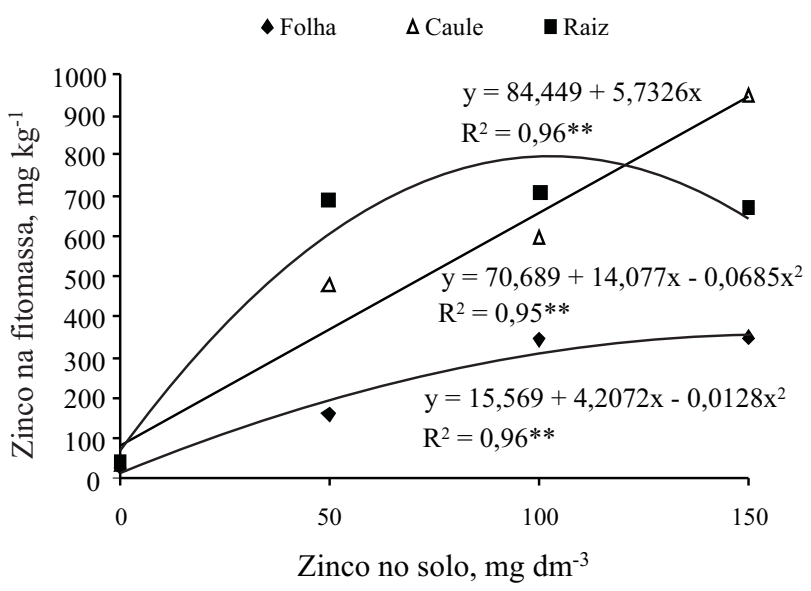

Figura 7 - Teores de zinco nas folhas, caule e raízes do pinhãomanso em função das doses de zinco aplicadas ao solo

no entanto, o acúmulo é muito menor. A explicação para tal fato é a mesma já comentada anteriormente para o acúmulo de $\mathrm{Cu}$, observado pelos autores.

$\mathrm{O}$ índice de translocação do $\mathrm{Cu}$ não foi influenciado de maneira significativa pelos tratamentos, porém, pode-se observar que nas plantas submetidas às três maiores doses do elemento, a translocação do mesmo, das raízes para a parte aérea, foi menor do que nas demais doses (Figura 8).

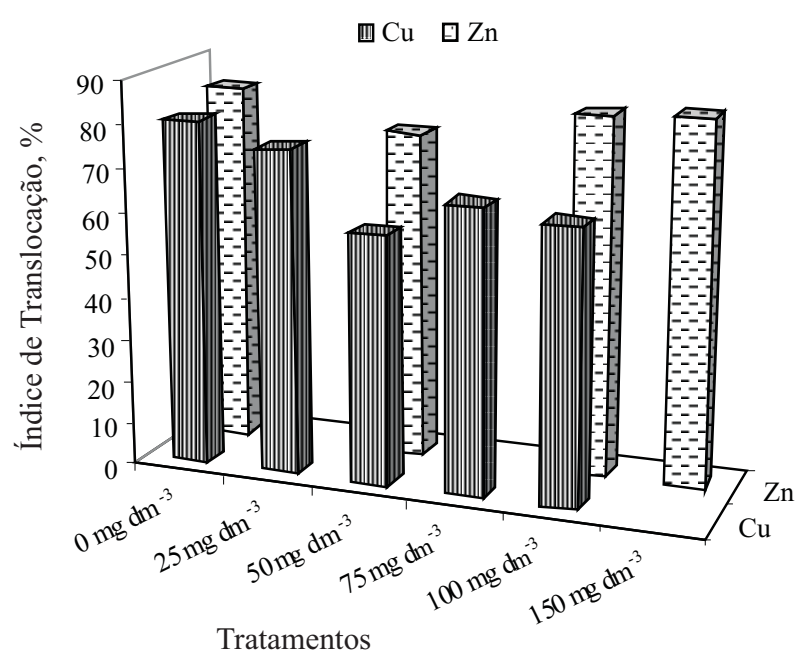

Figura 8 - Índice de translocação de cobre e zinco em pinhãomanso submetido aos níveis crescentes destes elementos aplicadas ao solo 
Segundo Kabata-Pendias e Pendias (1992), o Cu não é prontamente móvel na planta devido permanecer ligado fortemente às paredes celulares das raízes, sendo os órgãos jovens os primeiros a desenvolver sintomas de deficiência de $\mathrm{Cu}$. Todavia, a sua mobilidade nos tecidos vegetais pode aumentar com o nível de suprimento do elemento, o que não foi observado no presente trabalho (Figura 8). Vale ressaltar que, em geral, a partir do tratamento correspondente a $25 \mathrm{mg} \mathrm{dm}^{-3}$, na medida em que aumentaram as doses de $\mathrm{Cu}$ aplicadas ao solo, diminuiu o valor acumulado nas folhas (Tabela 3), o que se justifica pela diminuição no índice de translocação do elemento.

No que diz respeito ao $\mathrm{Zn}$, a variação dos índices de translocação em função dos tratamentos foi muito pequena e também não significativa (Figura 8). Comparando os índices de translocação dos dois elementos, aqueles correspondentes ao $\mathrm{Zn}$ foram superiores aos do $\mathrm{Cu}$, principalmente, para as doses iguais dos elementos adicionados ao solo (50 e $100 \mathrm{mg} \mathrm{dm}^{-3}$ de $\mathrm{Cu}$ e $\mathrm{Zn}$ ). Alguns autores consideram o Zn altamente móvel, outros atribuem a ele mobilidade intermediária. De fato, quando existe um grande suprimento de $\mathrm{Zn}$, muitas espécies de plantas translocam quantidades apreciáveis do elemento das folhas velhas para órgãos de crescimento.

\section{Conclusões}

1. As plantas de pinhão-manso durante o período experimental são tolerantes aos tratamentos utilizados, no entanto, doses de cobre e zinco no solo acima de 75 e $50 \mathrm{mg} \mathrm{dm}^{-3}$, respectivamente, depreciam o crescimento das mesmas.

2. Os acúmulos de cobre e zinco nas plantas de pinhãomanso obedeceram às seguintes ordens, respectivamente: folha $>$ raiz $>$ caule; caule $>$ folha $>$ raiz.

3. O índice de translocação do zinco foi maior que a do cobre nas plantas de pinhão-manso.

\section{Referencias}

ABICHEQUER, A. D.; BOHNEN, H. Eficiência de absorção, translocação e utilização de fósforo por variedades de trigo. Revista Brasileira de Ciência do Solo, v. 22, n. 01, p. 21-26, 1998.

ACCIOLY, A. M. A.; SIQUEIRA, J. O. Contaminação química e biorremediação do solo. In: NOVAIS, R. F.; ALVAREZ, V. H.; SCHAEFER, C. E. G. R. Tópicos em Ciência do Solo. Viçosa: Sociedade Brasileira de Ciência do Solo, 2000. p. 299-351.

ANDRADE, T. M. et al. Deficiência de micronutrients em mudas de Jatropha curcas L.: resultados preliminares. 2007.
Disponível em <http:/www.biodisiel.gov.br/docs/congresso 2007/agricultura>. Acesso em: 23 maio. 2009.

ANTOSIEWICZ, D. M. Adaptation of plants to an environment polluted with heavy metals. Acta Societatis Botanicorum Poloniae, v. 61, n. 02, p. 281-299, 1992.

ARRUDA, F. P. et al. Cultivo de pinhão-manso (Jatropha curcas L.) como alternativa para o semi-árido nordestino. Revista Brasileira de Oleaginosas e Fibrosas, v. 08, n. 01, p.789-799, 2008.

ASSISTÊNCIA Estatística (ASSISTAT). Download: versão 7.5 beta. 2008. Disponível em <http://www.assistat.com>. Acesso em: 18 maio de 2009.

BAKER, A. J. M. et al. Metal hyperaccumulator plants: a review of the ecology and physiology of a biological resource for phytoremediation of metal-polluted soils. In: TERRY, N.; BAÑUELOS, G. (Ed.). Phytoremediation of contaminated soil and water. Boca Raton: Lewis Publishers, 2000. p. 85-107.

BOWEN, H. J. M. Environmental chemestry of the elements. London: Academic Press, 1979. 333 p.

BURKEN, J. B. Fate and Partitioning in Vegetation: use of Tree Cores in Groundwater Analysis. Environmental Science Technology, v. 36, n. 21, p. 4663-4668, 2002.

COMPANHIA DE TECNOLOGIA DE SANEAMENTO AMBIENTAL (CETESB). Relação de áreas contaminadas no Estado de São Paulo. 2007. Disponível em: $<$ http://www.cetesb. sp.gov.br>. Acesso em: 18 de maio 2009.

CHAVES, L. H. G. et al. Zinco e cobre em pinhão manso. I. Crescimento inicial da cultura. Caatinga, v. 22, n. 03, p. 94-99, 2009a.

CHAVES, L. H. G. et al. Zinco e cobre em pinhão manso. II. Teores dos elementos em folhas e caule. Caatinga, v. 22, n. 03, p. 100-106, 2009b.

EMPRESA BRASILEIRA DE PESQUISA AGROPECUÁRIA (EMBRAPA). Centro Nacional de Pesquisa de Solos. Sistema brasileiro de classificação de solos. Brasília: Embrapa Produção de Informação; Rio de Janeiro: Embrapa Solos, 1999. 412 p.

FAUST, M. B.; CHRISTIANS, N. E. Copper reduces shoot growth and root development of creeping bentgrass. Crop Science, v. 40, p. 498-502, 2000.

GUSMAO, C. A. G. et al. Modificações no crescimento e na área foliar de plântulas de pinhão-manso (Jatropha curcas L.) ocasionadas por distúrbios nutricionais. Disponível em <http://www.biodise.gov.br/docs/congresso2007/ agricultura/56.pdf>. Acesso em: 23 maio 2009.

KABATA-PENDIAS, A.; PENDIAS, H. Trace elements in soils and plants. 2. ed. Boca Raton: CRC Press, 1992. 315 p.

KOPITTKE, P. M.; MENZIES, N. W. Effect of Cu toxicity on growth of cowpea (Vigna unguiculata). Plant and Soil, v. 279, n. 01/02, p. 287-296, 2006.

LAVIOLA, B. G.; DIAS, L. A. S. Teor e acúmulo de nutrientes em folhas e frutos de pinhão-manso. Revista Brasileira de Ciência do Solo, v. 32, n. 05, p. 1969-1975, 2008. 
MALAVOLTA, E. et al. Avaliação do estado nutricional das plantas: princípios e aplicações. Piracicaba: Potafos, 1997. 319 p.

MARSCHNER, H. Mineral nutrition of higher plants. 2. ed. San Diego: Academic, 1995. 902 p.

MATTIAZZO-PREZZOTO, M. E. Comportamento de cobre, cádmio, cromo, níquel e zinco adicionados a solos de clima tropical em diferentes valores de pH. 1994. 197 f. Tese (Livre Docência) - Escola Superior de Agricultura "Luiz de Queiroz", Piracicaba, 1994.

SATURNINO, H. M. et al. Cultura do pinhão-manso (Jatropha curcas L.). Informações Agropecuárias, v. 26, p. 44-78, 2005.

SIILVA, E. N. et al. Acúmulo de íons e crescimento de pinhãomanso sob diferentes níveis de salinidade. Revista Ciência Agronômica, v. 40, n. 02, p. 240-246, 2009.

SIMÃO, J. B. P.; SIQUEIRA, J. O. Solos contaminados por metais pesados: características, implicações e remediação. Informe Agropecuário, v. 22, n. 210, p. 18-26, 2001.
SOARES, C. R. F. S. et al. Acumulo e distribuição de metais pesados nas raízes, caule e folhas de mudas de arvores em solo contaminado por rejeitos de industria de zinco. Revista Brasileira de Fisiologia Vegetal, v. 13, n. 03, p. 302-315, 2001.

XIAOHAI, L. et al. Accumulation of $\mathrm{Pb}, \mathrm{Cu}$ and $\mathrm{Zn}$ in native plants growing on contaminated sites and their potential accumulation capacity in Heqing, Yunnam. Journal of Environmental Science, v. 20, n. 12, p. 1469-1474, 2008.

ZEITOUNI, C. F.; BERTON, R. S.; ABREU, C. A. Fitoextração de cádmio e zinco de um latossolo vermelhoamarelo contaminado com metais pesados. Bragantia, v. 66, n. 04, p. 649-657, 2007.

WENDT, C. W. Use of a relationship between leaf length and leaf area to estimate the leaf area of cotton (Gossypium hirsuntum L.), castors (Ricinus communis L.), and sorghum (Sorghum vulgare L.). Agronomy Journal, v. 59, n. 05, p. 484-486, 1967. 